\title{
Exploring healthcare professionals' perceptions regarding family-witnessed resuscitation in a hospital in Kigali, Rwanda
}

\author{
P Havugitanga, ${ }^{1}$ RN, MCC\&TN; P Brysiewicz, ${ }^{2} \mathrm{PhD}$ \\ ${ }^{1}$ Faculty of Nursing Sciences, Kigali Health Institute, Rwanda \\ ${ }^{2}$ School of Nursing and Public Health, University of KwaZulu-Natal, Durban, South Africa
}

Corresponding author: P Brysiewicz (brysiewiczp@ukzn.ac.za)

Background. The process of actively attempting to revive a patient in cardiac arrest while in the presence of family members is known as family-witnessed resuscitation (FWR). The positive benefits of having family members present during resuscitation have been documented.

Objective. To explore the perceptions of healthcare professionals regarding FWR in an intensive care unit (ICU) and an accident and emergency (A\&E) unit in a hospital in Kigali, Rwanda.

Methods. A qualitative approach was used to explore the participants' perceptions regarding FWR, using two semi-structured individual interviews conducted with each participant. The principle of saturation was applied, and a total of eight participants from two departments (ICU and A\&E) in a hospital in Kigali were included in this study.

Results. From the participants' responses at the beginning of the interview, it was evident that FWR was a new concept for them. The participants welcomed the idea by expressing their perceived benefits of FWR. They established that the hospital where the research was conducted did not have any policies or procedures currently in place, but felt that this practice might be beneficial to the families, the patient and the medical team. However, participants did raise various concerns related to the challenges of implementing the practice of FWR.

Conclusion. FWR is not currently practised in Rwanda and a number of recommendations are suggested in an attempt to introduce this practice as an option for Rwandan families.

S Afr J Crit Care 2014;30(1):18-21. DOI:10.7196/SAJCC.174

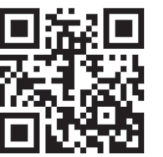

The process of activelyattempting to revive a patient in cardiac arrest while in the presence of family members is known as family-witnessed resuscitation (FWR). ${ }^{[1]}$ The positive benefits of having family members present during resuscitation have been documented in the literature. These benefits include the development of a bond with the resuscitation team, the provision of a more humane atmosphere allowing for closure, and the family's satisfaction of knowing that their family member is in safe hands. ${ }^{[2]} \mathrm{A}$ prospective, randomised controlled trial found a trend towards lower levels of anxiety, depression and grief after witnessed resuscitation among relatives. ${ }^{[1]}$ Proponents of FWR argue that distressed family mem- bers should not be denied the opportunity to be with their loved ones during their last moments.

Two European surveys, undertaken in collaboration with the European federation of Critical Care Nursing associations and the European Society of Paediatric and Neonatal Intensive Care ${ }^{[3,4]}$ have shown that, given a choice, most relatives of patients in the USA and the UK would choose to be present during resuscitation.

Research studies conducted with regard to the opinions of health professionals have showed that those approving of family presence said that it helped relatives to see the effort of the resuscitation team and that everything that could have been done had been done, which may lower the risk of litigation surrounding 
the resuscitation. ${ }^{[5]}$ Another idea was that it facilitated the grieving process, gave family members the opportunity to say goodbye, and promoted the family's acceptance of the death of their loved one. ${ }^{[6]}$

This practice has, however, sparked some controversy among emergency medical and intensive care staff worldwide ${ }^{[1]}$ and healthcare professionals are divided on whether family members should be present. ${ }^{[7]}$ Findings opposing FWR practice emphasise the increase of staff stress, inhibition of staff performance, legal implications and complaints from relatives ${ }^{[8]}$ However, a review of the literature suggests that the advantages of FWR for families outweigh the disadvantages, and that health professionals can support the practice without hindering the clinical care of patients. ${ }^{[9]}$

From the researcher's experience, allowing family members to remain with patients during resuscitation efforts is a relatively new concept in Rwanda. Common practice in most hospitals is that the patient is taken into a resuscitation room and the relatives are escorted outside the unit or to the visitors' corridor while health professionals work to resuscitate the patient. The health professionals update relatives on the patient's progress afterwards. In a case of death during resuscitation, the healthcare professionals try to make the body as presentable as possible by removing tubes, switching off the cardiac monitor and ventilator machine and covering the body before allowing the relatives to say goodbye to their loved one. In many hospitals, the resuscitation team does not return to meet the relatives.

\section{Objective}

The objective of this study was to explore the perceptions of healthcare professionals in the intensive care unit (ICU) and the accident and emergency (A\&E) unit regarding the practise of FWR.

\section{Methods}

A qualitative inquiry approach, using content analysis, was used. Two semi-structured interviews were conducted with each participant to explore their perceptions regarding FWR.

\section{Setting}

The study was conducted in ICU and A\&E unit in a 200-bed tertiary hospital in Rwanda. Resuscitation procedures are frequently carried out in the ICU and A\&E unit, and physicians and nurses working in these units also play an active part in the hospital resuscitation team. Hospital records indicate that a total of 46 resuscitations occurred within the hospital in the first 6 months of 2011. Of these resuscitation procedures, 27 (59\%) were conducted within the ICU and A\&E unit (M Joseph, personal communication, Jul 2011).

\section{Participants}

The participants included physicians and nurses (working both day and night duties) from the ICU and A\&E unit in the hospital. In the context of this study, a physician is a medical professional permanently working in either the ICU or A\&E unit as a general practitioner or specialist. A nurse is a person educated and licensed in nursing practice, registered by the Rwandan Nursing Council and working in the ICU or A\&E unit.

Purposive sampling was used to identify the physicians and nurses to be included in the study. The inclusion criteria were that the participants had to have been employed in either of the units for more than 6 months, and that they had been exposed to the resuscitation procedure more than twice in order to make sure that the participant had sufficient exposure. Specialised emergency and ICU training was not a criterion. Although data collection continued until data saturation was reached, it was anticipated that the researcher would interview at least three nurses and one physician from each unit. It was noted that the researcher was known to participants as he conducted his clinical practice in the same hospital.

\section{Data collection procedure}

After obtaining permission to conduct the research, appointments were made with the respective unit managers and heads of departments for the purpose of self-introduction, explaining the research topic and obtaining permission to meet with the staff members. Another appointment was then made with selected staff members of the ICU and A\&E unit who were willing to participate in this study, to obtain their written consent. It was agreed, at the researcher's request, that the interviews would be conducted while the participants were on duty and a quiet venue, free from distractions, was provided. A semi-structured interview guide was utilised to guide the interviews with each participant, and permission was obtained from the participants to record the interview on a voice recorder. The data recorded were later transcribed verbatim into written text for data analysis. At the beginning of each interview, the participants chose a pseudonym to ensure that their identity remained confidential. Between August and September 2011, two semi-structured interviews were conducted per participant; all interviews, each lasting approximately 30 minutes, were carried out by the researcher. First interviews were based on the interview guide, and second interviews were used to verify the interpretation of the data collected in the first interview. The interviews were all conducted in English as there is mandated use of English by staff in this hospital. The recorded interviews were transcribed into written text by the researcher, and a person with language expertise from a local university checked the transcripts for language. The data were then manually analysed using qualitative inductive content analysis to derive categories from the recorded data. ${ }^{[10]}$ The researcher identified and classified the data into different categories.

\section{Trustworthiness}

The researcher attempted to establish trust with participants so that they would contribute useful information during the data collection process. ${ }^{[1]}$ Participants were given the opportunity to refuse to participate in the study. Those who agreed to participate were interested and willing to take part in the study. The researcher aimed to establish a rapport in the opening moments of each session by indicating that there were no right or wrong answers to the questions and by encouraging the participants to be frank. Feedback on the categories emerging from the data was provided to the participants in the second interview in order to record their reactions and to explore whether the interpretations were a true representation of the participants' reality, thus validating the findings. ${ }^{[11]}$

\section{Ethics}

Permission to conduct the study was obtained from the research committee of the Kigali Health Institute and the study was approved by the ethics research committee of the hospital. Permission was also obtained from the management of the hospital. Participation was voluntary and prior written consent was obtained from the participants, who were informed of their right to withdraw from the research at any time. Confidentiality was assured through use of 
pseudonyms so that data could not be traced back to individuals. The data were kept in a secure place available only to the research team.

\section{Results}

Eight participants were interviewed. A profile of the participants is presented in Table 1.

Three categories emerged from the data:

- Participants' knowledge of FWR

- Perceived benefits of the practice of FWR

- Perceived challenges of implementing the practice of FWR.

\section{Participants' knowledge of FWR}

Participants' responses demonstrated that most of them were unsure of the meaning of the concept 'family-witnessed resuscitation' and how it was implemented in practice. The researcher asked each of the participants to explain what they understood by the term, and whether or how this practice is performed in their unit. There were a variety of responses and there appeared to be some confusion regarding the concept.

One participant explained: 'Witnessed resuscitation is when you have a patient who collapses in front of you and you are there when the arrest occurs in your presence.' (MAl)

Others explained that it is resuscitation initiated by health professionals: 'Witnessed resuscitation is resuscitation conducted by qualified persons or qualified group initiated and conducted by that same group.' (MUJADO)

Another participant defined FWR as doing resuscitation in the presence of colleagues (nurses or physicians): 'Witnessed resuscitation is doing resuscitation with other staff - a nurse or doctor watching what you are doing.' (KALISA)

The researcher then explained to each participant what FWR entailed before asking further questions and noted various emotional reactions displayed by the participants. While the researcher was clarifying the concept, he noticed various non-verbal cues (e.g. surprise, smiles and determination) on the faces of the participants. Once they knew what FWR meant, all of the participants said that there was no policy regarding FWR in the hospital. Some of the participants asked why the hospital did not have such a policy, which would allow the use of this practice in the hospital.

\section{Perceived benefits of the practice of FWR}

The researcher asked participants if they could identify any possible benefits of FWR in the ICU and A\&E unit.

'I think when you have a relative near to you when you are resuscitating ... the benefits firstly include [the] fact that relatives are watching whatever you are doing, and secondly it helps them psychologically because they are witnessing that you did the best you could'. (MAI)

'The benefits? Let me stand on the side of relatives. I can say that when relatives are witnessing the care given to the patient and all efforts made by medical team, it will help them to overcome their internal conflicts.' (JC1)

One participant suggested that a benefit of FWR would be reduced conflict between the medical team and the families, and it could possibly make it easier to break bad news to the families afterwards.

II see that it can reduce conflicts between relatives and medical team and it can also help to give information at the end of resuscitation procedure because the family has followed the extraordinary efforts made by the resuscitation team.' (MUJADO)

\section{Perceived challenges of implementing the practice of FWR}

The participants also described the many challenges they perceived in relation to FWR.

'As health professionals, we can't feel comfortable when we are doing a procedure and someone else is observing the team. One can have ... or be stressed because there is another person watching him. So we don't feel well ... we wish next of kin to stay far away from the resuscitation room such that we can perform our procedures very peacefully.' (KALISA)

Participants raised another challenge of implementing FWR, saying that families may feel uncomfortable or be traumatised while observing the different procedures that the medical team performs.

'Other thing is that during resuscitation we are doing invasive procedures to the patient: CPR, defibrillation and intubation ... those may traumatise relatives.' (MAl)

'There are some manoeuvres seen by relatives as harmful, like chest compressions ... the next of kin will perceive it like you are killing the patient.' (KALISA)

Table 1. Profile of participants

\begin{tabular}{|c|c|c|c|c|}
\hline Pseudonym & $\begin{array}{l}\text { Professional position } \\
\text { in the unit }\end{array}$ & $\begin{array}{l}\text { A\&E or ICU } \\
\text { experience (years) }\end{array}$ & $\begin{array}{l}\text { Approximate number } \\
\text { of resuscitations last } \\
\text { year }\end{array}$ & General comments \\
\hline MAI & Registered nurse & 6 & 8 & Has experience in ICU and $A \& E$ \\
\hline ZEC & Registered nurse & 4 & 6 & Only has ICU experience \\
\hline XENO & Registered nurse & 5 & 10 & $\begin{array}{l}\text { Completed a course on postcardiac surgery } \\
\text { care in ICU }\end{array}$ \\
\hline MUJADO & Registered nurse & 6 & 10 & $\begin{array}{l}\text { Has experience in A\&E and high dependency } \\
\text { unit }\end{array}$ \\
\hline JC1 & Medical officer & 2 & 6 & Only has ICU experience \\
\hline KALISA & Medical officer & 3 & 7 & Only has A\&E experience \\
\hline KATU & $\begin{array}{l}\text { Registered nurse and } \\
\text { unit manager }\end{array}$ & 10 & $>10$ & $\begin{array}{l}\text { Completed course in high-care nursing and } \\
\text { has experience in ICU }\end{array}$ \\
\hline NINA & $\begin{array}{l}\text { Registered nurse and } \\
\text { unit manager }\end{array}$ & 5 & 8 & $\begin{array}{l}\text { Completed short course in emergency } \\
\text { trauma nursing and has experience in } A \& E\end{array}$ \\
\hline
\end{tabular}


Other participants raised the concern that families witnessing the resuscitation could impede the performance of the resuscitation team and their presence may delay the decision of ending the resuscitation:

'From what I have observed ... when the relatives are around, they even jump on the patient ... crying, making noise and shaking the medical team asking them to continue ... even when the doctor decides to stop resuscitation.' (XENO)

Some of the participants expressed the concern that the resuscitation team may end up faced with a second casualty that they would be unable to handle while trying to resuscitate the patient.

'Relatives are not conversant with medical actions so they can be scared witnessing resuscitation, and the relative can be traumatised when the medical team is busy resuscitating the patient. If there is no one to help the relatives in case they collapsed, this could create another job which you are not able to handle at the time.' (MUJADO)

\section{Discussion}

The results of this study could provide useful information with regard to FWR within Africa, and especially in Rwanda. The study introduced the concept of FWR to the doctors and nurses involved in the study and highlighted its possible application in Rwanda. The findings reflected the current lack of knowledge regarding the concept as well as the lack of policy and strategies to guide staff practices related to FWR in the A\&E unit and ICU of the hospital. Although it is some 30 years since its inception, FWR proved to be a new concept for most of this study's participants. While healthcare professionals and families have many different opinions on this concept, the movement to FWR has progressed because of the ongoing public demand from families to be present during resuscitation efforts, and an increasing body of knowledge about its benefits. ${ }^{[8]}$ Regardless of this vast body of support, FWR is not a widespread practice and has not been universally accepted among healthcare professions. ${ }^{[12,13]}$ In the clinical settings of Rwanda, family members are often allowed to stay at the bedside of a patient to help care for them, but the family is excluded during resuscitation, and if the resuscitation effort fails, the doctors and nurses announce the death.

The findings of this study revealed that although the participants were not aware that such a practice existed, most of them were receptive to the idea of families being present during resuscitation and readily expressed their views on the possible benefits. Similar views have been documented in the literature where it was noted that FWR helps families to see the efforts of the resuscitation team and that everything that could have been done was done. ${ }^{[1,5]}$ Many researchers support that idea that FWR facilitates the grief process in the case of unsuccessful resuscitation. ${ }^{[6,7,12]}$

However, even though participants identified various beneficial aspects of FWR, they also identified many challenges to implementing this practice, which were in accordance with those documented in the literature. Studies have shown that FWR can have an effect on the resuscitation team, and concerns of increased stress for health professionals and the fear of litigation exist. ${ }^{[12-14]}$ Many researchers have highlighted that the presence of family members could increase the stress on healthcare professionals, ${ }^{[1,13-15]}$ family presence during resuscitations could lead to an increase in complaints and/or litigation and FWR of a loved one could lead to psychological trauma in the witness. ${ }^{\left[{ }^{[13]}\right.}$ Furthermore, it has been documented in the literature that family members who witness resuscitation might attempt to delay making the decision to end the resuscitation procedure. ${ }^{[15]}$

In today's healthcare environment, involving the family in the care of the patient is important for quality healthcare. Participants in this study showed willingness to share their views and perceptions on benefits and challenges of implementing the practice of FWR and appeared interested regarding FWR. Some participants asked the researcher why their hospital did not have policies to govern this.

\section{Recommendations}

Implementation of training related to FWR for health professionals working in A\&E unit and ICU is needed, and the formulation of realted policy and procedure should help as guidance of this practice. Further research regarding FWR needs to be done in Rwanda with more focus on the views and perceptions of the patients and their families.

\section{Study limitations}

The presence of the researcher could have influenced the participants'responses, in that the participants may have provided answers in accordance with what they thought the researcher wanted to hear. The use of a tape recorder during the interviews could have caused the participants to be less spontaneous in their responses.

\section{Conclusion}

FWR appears to be a new concept in Rwanda and participants expressed caution about the practice for a number of reasons. FWR is not currently practised in Rwanda and it is recommended that the practice is introduced as an option for Rwandan families.

\footnotetext{
References

. Ong MEH, Chung WL, Mei SE. Comparing attitudes of the public and medical staff towards witnessed resuscitation in an Asian population. Resuscitation 2006;73(1):103-108. [http:// dx.doi.org/10.1016/j.resuscitation.2006.08.007]

2. Wagner M. Lived experience of critically ill patients' family members during cardiopulmonary resuscitation. Am J Crit Care 2004;13(5):416-420.

3. Fulbrook JW, Albarran JM, Latour J. A European survey of critical care nurses' attitudes and experiences of having family members present during cardiopulmonary resuscitation. Int Nurs Stud 2004;42(5):557-568. [http://dx.doi.org/10.1016/j.jijnurstu.2004.09.012]

4. Fulbrook P, Latour J, Albarran J, de Graaf W, Lynch F. The presence of family members durin cardiopulmonary resuscitation. Eur J Cardiovasc Nurs 2007;6(4):255-258. [http://dx.do org/10.1016/j.ejcnurse.2007.07.003]

5. Basol R, Ohman, K, Simones J, Skillings K. Using research to determine support for a policy on family presence during resuscitation. Dimens Crit Care Nurs, 2009;28(5):237-247. [http:// dx.doi.org/10.1097/DCC.0b013e3181ac4bf4]

6. Demir F. Presence of patients' families during cardiopulmonary resuscitation: Physicians'

Demir F. Presence of patients' families during cardiopulmonary resuscitation: Physicians
and nurses' opinions. J Adv Nurs 2008;63(4):409-416. [http://dx.doi.org/10.1111/j.1365and nurses opinions.

Marrone L, Fogg C. Family presence during resuscitation. Nursing 2005;35(8 Suppl E D):21-27.

8. Mian P, Warchal S, Whitney S, Fitzmaurice J, Tancredi D. Impact of a multifaceted intervention on nurses' and physicians' attitudes and behaviours toward family presence during resuscitation Crit Care Nurse 2007;27(1):52-61

9. Shaw K, Ritchie D, Adams G. Does witnessing resuscitation help parents come to terms with the death of their child? A review of the literature. Intensive Crit Care Nurs 2011;27(5):253-262. [http://dx.doi.org/10.1016/j.iccn.2011.05.001]

0. Pope C, Ziebland S, Mays N. Qualitative research in health care: Analysing qualitative data. BMJ 2000;320(7227):114-116.

11. Shenton A. Strategies for ensuring trustworthiness in qualitative research projects. Education for Information 2004:22:63-75.

12. Chapman R, Watkins R, Bushby A, Combs S. Family-witnessed resuscitation: Perception of nurses and doctors working in an Australian emergency department. ISRN Emergency Medicine 2012; Article ID 369423. [http://dx.doi.org/10.5402/2012/369423]

13. Goodenough TJ, Brysiewicz P. Witnessed resuscitation - exploring the attitudes and practice of the emergency staff working in level 1 emergency departments in the province of KwaZuluNatal Curationis 2003:26(2):56-63.

14. Köberich S, KaltwasserA, Rothaug O, Albarran J. Family-witnessed resuscitation - experience and attitudes of German intensive care nurses. Nurs Crit Care 2010;15(5):241-250. [http:// dx.doi.org/10.1111/j.1478-5153.2010.00405.x

15. Gordon ED, Kramer E, Couper I, Brysiewicz P. Family-witnessed resuscitation in emergency
} departments: Doctors' attitudes and practices. S Afr Med J 2011:101(10):765-767. 